\title{
A Modified Intracorporeal Billroth-I Anastomosis After Laparoscopic Distal Gastrectomy for Gastric Cancer: A Safe and Feasible Technique
}

\author{
Changming Huang, MD, Mi Lin, Qiyue Chen, Jianxian Lin, Chaohui Zheng, Ping Li, Jianwei Xie, Jiabin Wang, \\ Jun Lu, Tan Chen, and Xintao Yang
}

Department of Gastric Surgery, Fujian Medical University Union Hospital, Fuzhou, Fujian Province, China

\begin{abstract}
Background. The delta-shaped gastroduodenostomy, an intracorporeal Billroth-I anastomosis after laparoscopic distal gastrectomy and using only endoscopic linear staplers, has been increasingly adopted by gastrointestinal surgeons. ${ }^{1-5}$ We modified this technique to simplify operation procedures and reduce surgical trauma in patients with gastric cancer.

Methods. After the stomach and duodenum were transected in predetermined positions, small incisions were made on the greater curvature of the remnant stomach and the posterior side of the duodenum. The forks of the stapler in each incision were closed and fired following approximation of the posterior walls of the gastric remnant and duodenum. The involution of the common stab incision was accomplished only by the instruments of the surgeon and assistant, and the duodenal cutting edge was completely resected when the common stab incision was closed with the stapler, thus decreasing the anastomotic weak point and avoiding poor blood supply to the duodenal stump. The above procedure was performed for 41 patients with stage cT1-4a disease.

Results. Mean operation time was $143.4 \pm 23.4 \mathrm{~min}$, mean anastomosis time was $13.9 \pm 2.8 \mathrm{~min}$, mean blood loss was $34.6 \pm 20.8 \mathrm{ml}$, and mean times to first flatus, fluid diet, and soft diet were $3.5 \pm 1.3,5.1 \pm 1.2$, and
\end{abstract}

Electronic supplementary material The online version of this article (doi:10.1245/s10434-014-3862-8) contains supplementary material, which is available to authorized users.

(C) Society of Surgical Oncology 2014

First Received: 23 April 2014;

Published Online: 27 June 2014

C. Huang, MD

e-mail: hcmlr2002@163.com
$8.1 \pm 4.3$ days, respectively. No patient experienced any anastomosis-related complications, such as anastomotic leakage, anastomotic stricture, or anastomotic hemorrhage. At a median follow-up of 10 months, no patient had died or experienced recurrent or metastatic disease.

Conclusions. The modified technique was technically safe and feasible, with acceptable surgical outcomes, in patients with gastric cancer.

DISCLOSURE We were funded by the National Key Clinical Specialty Discipline Construction program of China (No. [2012] 649).

\section{REFERENCES}

1. Kanaya S, Gomi T, Momoi H, et al. Delta-shaped anastomosis in totally laparoscopic Billroth I gastrectomy: new technique of intraabdominal gastroduodenostomy. J Am Coll Surg. 2002;195: 284-7.

2. Okabe H, Obama K, Tsunoda S, Tanaka E, Sakai Y. Advantage of completely laparoscopic gastrectomy with linear stapled reconstruction: a long-term follow-up study. Ann Surg. 2013;00:1-8.

3. Kim JJ, Song KY, Chin HM, Kim W, Jeon HM, Park CH, Park SM. Totally laparoscopic gastrectomy with various types of intracorporeal anastomosis using laparoscopic linear staplers: preliminary experience. Surg Endosc. 2008;22:436-42.

4. Kim MG, Kim KC, Kim BS, Kim TH, Kim HS, Yook JH, Kim BS. A totally laparoscopic distal gastrectomy can be an effective way of performing laparoscopic gastrectomy in obese patients (body mass index $\geq 30$ ). World J Surg. 2011;35:1327-32.

5. Kanaya S, Kawamura Y, Kawada H, Iwasaki H, Gomi T, Satoh S, Uyama I. The delta-shaped anastomosis in laparoscopic distal gastrectomy: analysis of the initial 100 consecutive procedures of intracorporeal gastroduodenostomy. Gastric Cancer. 2011;14: $365-71$. 